Med Princ Pract 2014;23:96-97

DOI: $10.1159 / 000353146$

\section{Spinal Tuberculosis: Which Is the Best Surgical Approach?}

Sanjay Meena, Samarth Mittal, Buddhadev Chowdhary

Department of Orthopaedics, All India Institute of Medical Sciences, New Delhi, India

We read the article entitled 'Outcomes of different surgical procedures in the treatment of spinal tuberculosis in adults' by Cui et al. [1] with great interest. Despite being an age old disease debate still surrounds the choice of approach. The authors concluded that posterior approach was superior to anterior approach for correcting deformity and maintaining correction. However, this conclusion is drawn from study groups that were not comparable from the beginning. There were statistically significant differences in the preoperative kyphosis angle in the anterior and posterior groups. Hence, the conclusion may not be appropriate.

The anterior approach popularized by Hodgson et al. [2] in 1960 is currently considered the gold standard for debridement and decompression in Pott's spine [3]. Advocates of the traditional anterior approach cite the ability to directly access the disease pathology and perform decompression, the fact that there is less muscle dissection and the ability to place a large graft under compressive load for fusion $[2,4]$. In the study of Cui et al. [1], anterior instrumentation was found to be inferior to posterior instrumentation. One of the reasons given by the authors was that the screws in the vertebral body cannot provide the same strength as the pedicle screws due to osteoporosis of the vertebral body caused by spinal TB. We disagree with the authors, as the screws were put into the normal healthy vertebral body and the affected vertebrae were removed. If there were osteoporosis of the vertebral body, then the hold of the posterior screw would also be poor.

The vertebra level operated on and the range of kyphosis angle in each group have not been mentioned. The anterior approach should be avoided in patients with lesions above T5 (as instrumentation above T4 body is difficult), in patients with kyphosis of more than $60^{\circ}$ (anterior-only correction causes spinal lengthening), in patients with disease involving the posterior elements and in patients with a bad preoperative chest condition. It would be interesting to know how the authors managed the 28 patients with a kyphosis angle of between 61 and $70^{\circ}$.

The size of paraspinal abscess decided the choice of approach. The cases lacking a large paraspinal abscess and without lumbosa- cral TB were subjected to anterior radical debridement and strut grafting and instrumentation, while cases with a large paraspinal abscess, especially lumbar TB, were given the surgical treatment of posterior instrumentation. The differential selection of the patients in each group may itself have influenced the results.

In group B (posterior approach), either a titanium cage filled with morcelized rib bone or large autoilliac or costal grafting were used. What were the criteria for choosing either of them?

One hundred and eighty-one patients with spinal TB were included in the study. Of these, only 25 patients had a neurological deficit. What was the indication for surgery in the other patients? They could very well have been managed conservatively or with a middle-path regimen [5]. The development of anti-TB drugs has revolutionized the treatment of patients with spinal $\mathrm{TB}$, as most patients do not have extensive destruction of bone, and sequestration can be successfully treated conservatively with chemotherapy, external bracing and prolonged rest [6].

Spinal TB with the lesion situated in the thoracic spine is more prone to develop kyphosis. In their study [1], the majority of patients in group A had TB in the dorsal spine while those in group $\mathrm{B}$ mostly had lesions in the lumbar spine. The poor results in group A cannot be attributed to instrumentation alone.

The surgical time and blood loss which are critically important parameters for the choice of approach were not mentioned. Although the mean age was mentioned, the age range in each group was not. In children and young adults, vertebral destruction is more severe because most bone is cartilaginous. In addition, angulation is more significant due to the growth retardation of the anterior column and unrestricted growth of the posterior column.

\section{References}

1 Cui X, Ma YZ, Chen X, et al: Outcomes of different surgical procedures in the treatment of spinal tuberculosis in adults. Med Princ Pract 2013, DOI:10.1159/000346626.

- Hodgson AR, Stock FE, Fang HS, et al: Anterior spinal fusion: the operative approach and pathological findings in 412 patients with Pott's disease of the spine. Br J Surg 1960;48:172-178.

- 3 Tuli SM: Tuberculosis of the spine: a historical review. Clin Orthop Relat Res 2007;460:29-38.

4 Benli T, Kaya A, Acaroglu E: Anterior instrumentation in tuberculous spondylitis: is it effective and safe? Clin Orthop Relat Res 2007;460:108116.

5 Tuli SM: Results of treatment of spinal tuberculosis by 'middle path' regime. J Bone Joint Surg Br 1975;57:13-23.

-6 Dai LY, Jiang LS, Wang W, et al: Single-stage anterior autogenous bone grafting and instrumentation in the surgical management of spinal tuberculosis. Spine (Phila Pa 1976) 2005;30:2342-2349.

\section{KARGER}

E-Mail karger@karger.com www.karger.com/mpp (c) 2013 S. Karger AG, Base 1011-7571/14/0231-0096\$39.50/0

Karger 0 pen access

This is an Open Access article licensed under the terms of the Creative Commons Attribution-NonCommercial 3.0 Unported license (CC BY-NC) (www.karger.com/OA-license) applicable to the online version of the article only. Distribution permitted for non-commercial purposes only.

\section{Sanjay Meena}

Department of Orthopedics, All India Institute of Medical Sciences New Delhi 110029 (India)

E-Mail sanjaymeena@hotmail.com 


\section{Reply}

Xu Cui, Yuan Zheng Ma, Xing Chen, Xiao Jun Cai, Hong Wei Li, Yi Bing Bai

Department of Orthopedics, 309th Hospital of PLA, Beijing, China

We thank Dr. Meena and colleagues for their interest in our study. We note that there were statistically significant differences in the preoperative kyphosis angle in the anterior and posterior groups because there were more patients with thoracic spinal tuberculosis (TB) in the anterior group than in the posterior group, who had physiological kyphosis [1]. It is a fact that the spinal TB rarely affects the pedicle part of the vertebra, so the pedicle screw is stronger than the vertebral screw when the vertebra is infected by TB. The 28 patients with a kyphosis angle between 61 and $70^{\circ}$ were managed by posterior instrumentation with posterior column shortening along with simultaneous or staged anterior radical debridement plus bone grafting $[2,3]$. The size of the paraspinal abscess governed the choice of approach, but did not affect the outcome of the instrumentation. Lumbosacral TB only in the posterior group may have influenced the results. The criteria for choosing morcelized rib bone or large autoilliac or costal grafting is based on the location and the size of the spinal TB [4]. It is true that only 25 patients had a neurological deficit, but the other patients were also candidates for surgery because of their symptoms, including refractory pain and kyphosis deformity of $>30^{\circ}$ unresponsive to conservative treatment [5]. Anterior instrumentation is used more often in the thoracic region, which has support from the bony thorax and is more stable than other areas, but the correction loss was still greater than that in the posterior group, as shown by our results. Surgical time and blood loss were not mentioned due to an error in the text.

\section{References}

1 Cui X, Ma YZ, Chen X, et al: Outcomes of different surgical procedures in the treatment of spinal tuberculosis in adults. Med Princ Pract 2013, DOI: $10.1159 / 000346626$.

- Wang X, Li J, Lü G, et al: Single-stage posterior instrumentation and anterior debridement for active tuberculosis of the thoracic and lumbar spine with kyphotic deformity. Int Orthop 2012;36:373-380.

-3 Rajasekaran S, Shanmugasundaram TK: Prediction of the angle of gibbus deformity in tuberculosis of the spine. J Bone Joint Surg Am 1987;69: 503-509.

4 Zhang H, Shu Huang, Hubing Guo, et al: A clinical study of internal fixation, debridement and interbody thoracic fusion to treat thoracic tuberculosis via posterior approach only. Int Orthop 2012;36:293-298.

5 Li M, Du J, Meng H, et al: One-stage surgical management for thoracic tuberculosis by anterior debridement, decompression and autogenous rib grafts, and instrumentation. Spine J 2011;11:726-733.

Xu Cui, MD

Department of Orthopedics

309th Hospital of PLA 17\# Heishan Hu Road

Beijing 100091 (China)

E-Mail cuixuprossor@163.com 